\title{
Familial clustering of the ataxic form of Creutzfeldt-Jakob disease with Hirano bodies
}

\author{
L CARTIER, ${ }^{*}$ S GÁLVEZ,† DC GAJDUSEK $\ddagger$
}

From the Department of Neurology and Neuropathology, Hospital del Salvador, ${ }^{*}$ Department of Neurology, Instituto de Neurocirugía e Investigaciones Cerebrales, $\uparrow$ Santiago de Chile, Chile and Laboratory of Central Nervous System Studies, National Institute of Neurological and Communicative Disorders and Stroke, $\ddagger$ NIH, Bethesda, Maryland, USA

SUMMARY A family cluster of the ataxic form of Creutzfeldt-Jakob disease with one probable and $\overbrace{}^{\infty}$ two autopsy proven cases that occurred in a single generation between 1974 and 1982 is $\vec{\circ}$ reported. The clinical characteristics of the cases are closely similar to those of kuru patients, with $\vec{\overrightarrow{ }}$ a fair correlation between the prominent truncal ataxia and the intense devastation of the cerebellar cortex most marked in the vermis. Pathologically, the marked hippocampal involvement rarely seen in typical transmissible Creutzfeldt-Jakob disease and the finding of Hirano bodies in the Ammon's horn without specific Alzheimer's senile changes are noteworthy features.

In 1965 Brownell and Oppenheimer ${ }^{1}$ grouped under the heading of the ataxic-cerebellar form of Creutzfeldt-Jakob disease four personal cases and six similar observations previously reported by other authors. The ten cases were characterised by outstanding cerebellar ataxia and selective cell loss of the granular layer of the cerebellum. Subsequently, several cases related to the ataxic form of Creutzfeldt-Jakob disease have been reported in Europe, USA and Japan, while most cases of Creutzfeldt-Jakob disease with kuru plaques, ${ }^{2}$ one of them diagnosed in Chile, ${ }^{3}$ can be included within this anatomoclinical variant. All these cases were sporadic, with the exception of case 2 of Zarranz et al. ${ }^{4}$ We report three personal cases of CreutzfeldtJakob disease which occurred in a single family and presented with progressive cerebellar ataxia, late dementia, absence of pyramidal-extrapyramidal signs, mild or absent myoclonus and no demonstrable periodic EEG abnormalities. Pathologically, in addition to the typical lesions of Creutzfeldt-Jakob disease mostly involving the cerebellar cortex, the brain of both histologically proven cases displayed unusual hippocampal sponginess and Hirano bodies in Ammon's horn.

Address for reprint requests: Dr Gálvez, Instituto de Neurocirugia e Investigaciones Cerebrales. PO Box 3717, Santiago de Chile.

Received 5 April 1984 and in final revised form 12 August 1984. Accepted 23 August 1984

\section{Case reports}

Figure 1 shows the pedigree of family YEsP with the thref affected sibs in generation II. The propositus (II-4) wast 48-year-old woman who died in 1974 after a 9 mon illness. The clinical onset and the subsequent 7 mont通 $\cong$ were characterised by slowly progressing unstable gait duef. $\vec{\bullet}$ to a predominantly truncal ataxia. Mild impairment of memory for recent events, irritability and hypochondria were interpreted as psychoreactive symptoms. However, 2 궁 months before death the patient was clearly demented and unable to stand or walk. In addition to cerebellar signs,

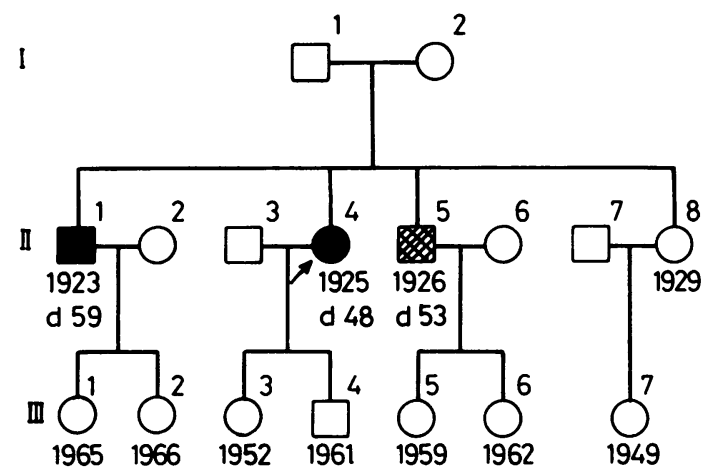

Fig 1 Pedigree of family YEsP with three sibs dying of the cerebellar form of Creutzfeldt-Jakob disease between 1974-1982. In patients II-1 and II-4 the diagnosis was verified by necropsy. Patient II-5 is a clinically probable Creutzfeldt-Jakob disease. 
myoclonic jerks in both upper extremities, bilateral palmomental reflexes and slight distal amyotrophy were observed. Deep reflexes and plantar responses were normal until death which occurred suddenly.

Routine blood tests and CSF examination were normal. Serial EEGs revealed unspecific and diffuse slow theta and delta waves. Air encephalogram showed mild cortical atrophy and slightly enlarged lateral ventricles. Postmortem examination did not show the cause of sudden death. Brain weight was $1350 \mathrm{~g}$ and both lateral ventricles were moderately enlarged. Microscopically, the cytoarchitecture was well preserved. In the frontal and occipital cortices, mild loss of neurons, slight and spotty spongiosis and astrocytosis were seen. Parietal and temporal cortices showed slight microspongiosis and moderate gliosis without neuronal changes. Similar, although somewhat more marked lesions were observed in the hippocampi, mostly involving the pyramidal layer of Sommer's sector. The parahippocampal cortex also presented diffuse spongiform changes and astrocytosis. Distinctly extraneuronal and strongly eosinophilic rod-like structures with longitudinal striations (Hirano bodies) were seen immediately adjacent to the pyramidal neurons in Sommer's sector (fig 2).

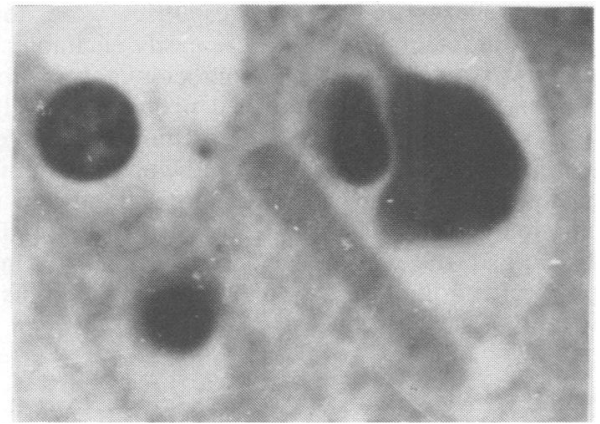

Fig 2 An Hirano body adjacent to a pyramidal neuron in Sommer's sector of patient II-4 (haematoxylin-eosin).

$(\times 500)$

Neurofibrillary tangles and senile plaques were not found. The caudate nucleus showed intense spongiosis, loss of neurons and astrogliosis, as did the putamen. The globus pallidus was unchanged. Pronounced spongiosis, nerve cell depletion and astrocytic proliferation involved the anterior and dorsomedial nuclei of the thalamus, while other thalamic nuclei were minimally affected. Severe changes were observed throughout the cerebellar cortex, specially in the vermis (fig 3). There was intense pallor of the granular layer with marked depletion of granule cells. The Purkinje cells were reduced in number and many showed axonal degeneration and dendritic thickening with silver stains. Moderate to severe spongiosis involved the molecular layer and a great number of Bergmann's nuclei was present. In the dentate nucleus the number of nerve cells was reduced and there was moderate gliosis. The substantia nigra and the motor nuclei of the brain stem had moderate gliosis and degenerative changes of the neurons, while the colliculi showed moderate spongiosis. Most neurons of the locus ceruleus were not pigmented. No significant changes were seen in the spinal cord. The blood vessels did not show structural changes.

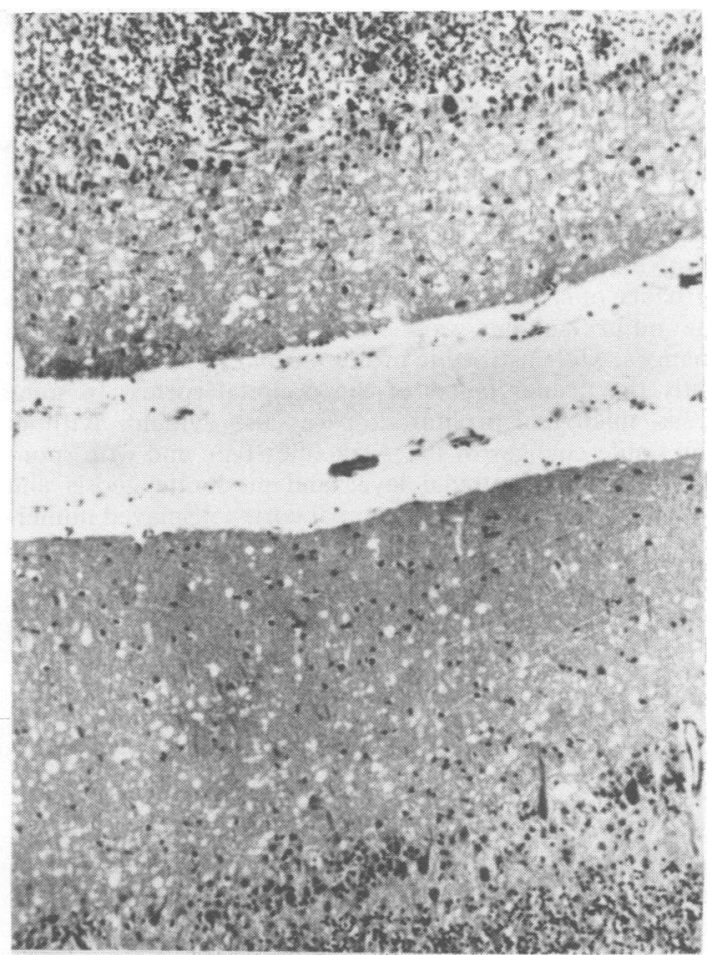

Fig 3 Cerebellar cortex (vermis) of patient II-4 showing diminished number of granule cells, loss and degeneration of Purkinje cells and intense spongiosis of the molecular layer with glial proliferation (haematoxylin-eosin). ( $\times 50)$

Patient II-1 was a 59-year-old man whose clinical onset occurred in December 1981, 7 years and 8 months after the death of his sister (II-4), and one month after an uncomplicated haemorrhoidectomy. He became irritable, uninterested and forgetful. In April 1982 memory loss and unsteadiness of the legs developed. On admission to hospital he was partially orientated in time and place and slightly euphoric but cooperative. He could read, write and do sums, but his memory was poor for recent events. The gait was unstable, but he could walk without support and Romberg's sign was negative. No other abnormal neurological signs were elicited. Routine blood tests were irrelevant. CSF examination showed moderate increase of protein content $(0.64 \mathrm{~g} / \mathrm{l})$. An initial EEG recorded diffuse theta waves and absent alpha rhythm. Computed tomography showed normal ventricles and slight cortical atrophy of both frontal lobes. The disease progressed rapidly and in July 1982 unaided walking was impossible because of severe truncal cerebellar ataxia, while finger-to-nose and heel-to-knee tests appeared moderately ataxic in left limbs. In the last month of life, speech became dysarthric and paraphasic, there was constructional apraxia, loss of sphincter control and marked mental deterioration. In both arms myoclonic jerks and mild distal amyotrophy were observed. The deep reflexes were hypoactive, both plantar responses were flexor and the muscle tone was 
rather flaccid. Bilateral palmomental reflexes were easily elicited. Serial EEGs recorded slow tracings only.

Death occurred on August 25, 1982, after an illness of about 8 months. The cause of death was bronchopneumonia. The brain weighed $1380 \mathrm{~g}$ and on gross examination slight widening of sulci and unchanged gyri were seen over the frontal areas. Microscopically, mild loss of neurons and slight microspongiosis and astrocytosis involved the cerebral cortex; however, there was no disturbance of lamination. In the frontal and occipital cortices the outer laminae were more affected by spongiform changes, while astrocytic proliferation involved predominantly the deeper layers of the occipital cortex. In some areas, microglial proliferation was also evident. Without any senile changes of the Alzheimer type and with spongiosis of the pyramidal layer and moderate gliosis and neuronal losses, the hippocampal cortex displayed numerous Hirano bodies in Sommer's sector (fig 4). The

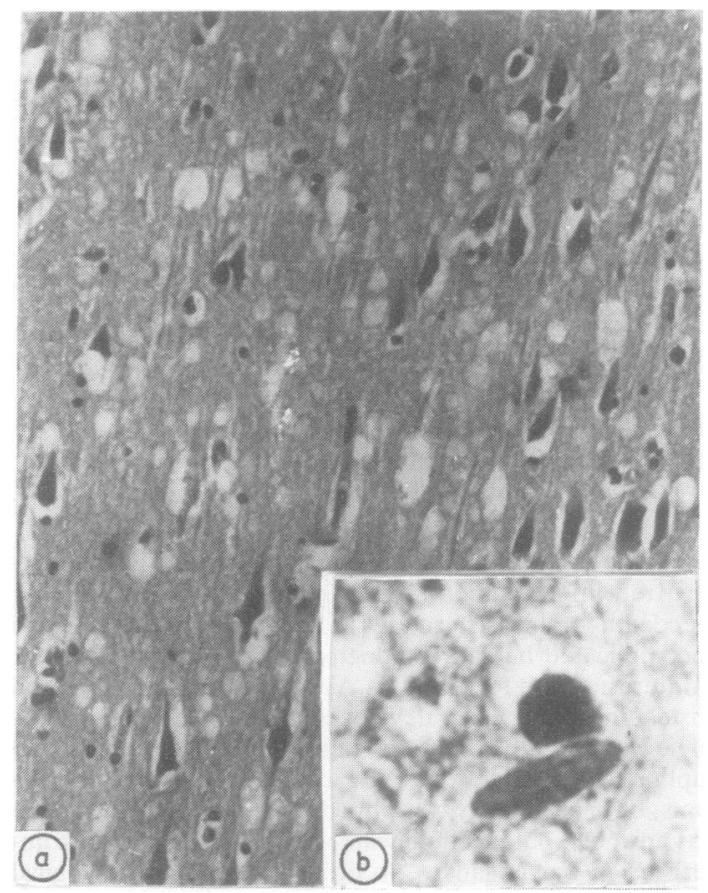

Fig 4 (A) Marked spongiosis of the pyramidal layer and moderate gliosis and loss and degeneration of neurons in the hippocampal cortex of patient II-1 (haematoxylin-eosin). $(\times 100)(B)$ An Hirano body adjacent to a shrunken neuron in the hippocampus of patient II-1

(haematoxylin-eosin). $(\times 500)$

thalamus was severely affected by intense loss and degeneration of neurons, gliosis and spongiosis most pronounced in the medial nuclei. The striatum showed marked spongiosis and astrocytosis and many neurons were shrunken or missing, but the globus pallidus was intact. Intense gliosis and minimal spongiosis were seen in some hypothalamic nuclei, while moderate neuronal depletion and gliosis involved the mammillary bodies. The changes observed in the brain stem consisted of a severe loss degeneration of neurons of the substantia nigra, free extracellular pigment and abundant Marinesco bodies. In the cerebellar cortex the granule cells were severely diminished in number. Similarly, marked loss of Purkinje cells and many axonal torpedos were observed. More than moderate spongiosis involved the molecular layer and there was widespread microglial proliferation. Those changes were observed predominantly in the vermis. The dentate nucleus had minor cell depletion and gliosis, without spongiosis. Vascular changes were absent. The spinal cord was not available for examination.

Patient II-5 was the youngest of the three affected sibs. He was a 53-year-old man at the time of death which occurred in December 1979, approximately 10 months after the clinical onset. The first 9 months of his disease were characterised by a rapidly progressing gait disturbance with no apparent cause and subsequent memory loss. During a short checkup in hospital he appeared well orientated and cooperative, answered questions appropriately, but showed some memory disturbances. His gait was grossly ataxic and Romberg's sign was positive, but no nystagmus was noted. Deep reflexes were hypoactive and abdominal reflexes and plantar responses were normal. Bilateral palmomental reflexes were easily elicitable, muscle tone was unchanged, and myoclonus was absent. Analysis of CSF showed increased protein $(0.7 \mathrm{~g} / \mathrm{l})$, air studies revealed slight enlargement of both lateral ventricles and the EEG showed a preserved alpha rhythm inter-市 rupted by diffuse theta waves. Routine blood and urine? examination was normal. At the request of the family he was discharged with progressive deterioration in his mentab and physical condition. He died at home two months later and necropsy was not done.

\section{Discussion}

The clinical spectrum of typical Creutzfeldt-Jakob disease includes rapidly progressive dementia, signs of higher cortical dysfunction, marked myoclonus, choreiform or athetotic movements, pyramidal and extrapyramidal signs and visual disturbances. Cerebellar signs may be seen early or late in the course of the disease. By contrast, in the cerebellar form of Creutzfeldt-Jakob disease a relatively "pure" limb and truncal ataxia is the prominent neurologic disturbance in the most part of the clinical course while myoclonus, mental deterioration and equivocal signs of pyramidal involvement appear in an advanced stage, when the patients are no longer able to stand or walk. This particular mode of clinical onset and its temporal sequence so markedly different from those of the typical transmissible Creutzfeldt-Jakob disease may lead to the initial confusion with hysteria, primary spino-cerebellar degeneration or tumour of the posterior fossa. Furthermore, in most cases, as in the patients reported here, the EEG examination does not show the characteristic periodic pattern currently seen in 
Creutzfeldt-Jakob disease. This is probably because the deep structures of the brain are most severely affected. Such distribution of the pathological changes is also seen in human kuru, where periodic EEG abnormalities have not been described ${ }^{5}$ and with which the ataxic type of Creutzfeldt-Jakob disease shares remarkable clinical and neuropathological similarities. ${ }^{6}$ Thus, in kuru patients the degenerative changes of the cerebellum are located mainly in the vermis, as occurred in our two definite cases and in the patients reported by Brownell and Oppenheimer $^{1}$ and by Michel et al. ${ }^{7}$ This peculiar involvement of the vermis accounts for the predominantly truncal ataxia that characterises kuru and the ataxic form of Creutzfeldt-Jakob disease.

While brains from typical Creutzfeldt-Jakob disease show widespread lesions in the cerebral cortex with less or no hippocampal involvement, a noteworthy pathological feature of our two definite cases is the finding of marked spongiform changes in the hippocampi, a finding that has been also described in other patients dying of the ataxic form of Creutzfeldt-Jakob disease. ${ }^{17-9}$ Since memory disturbances develop early in the course of the ataxic stage of the disease, the question arises of the possible relationship between the severe bilateral hippocampal involvement and the amnesic phenomena.

Of particular interest is the presence of Hirano bodies in the Ammon's horn of our two necropsied patients without specific changes of Alzheimer's type. The significance of Hirano bodies is unknown. They are more frequently observed in normal.aged individuals and in patients with Pick's disease or Alzheimer's disease, ${ }^{10}$ as well as in the Guamanian amyotrophic lateral sclerosis-Parkinson dementia complex." They have been occasionally described in cerebral cortex adjacent to gliomas ${ }^{12}$ and in the anterior horns of the spinal cord from patients with motor neuron disease.$^{13}$ However, in addition to the demonstration of Hirano bodies in the two patients reported here, they have been also observed in the hippocampi of two other cases of definite Creutzfeldt-Jakob disease, ${ }^{1014}$ in the brain biopsy of another Creutzfeldt-Jakob disease patient, ${ }^{15}$ as well as in the cerebral cortex of scrapie-infected mice ${ }^{16}$ and in the cerebellar cortex of natural and experimental kuru. ${ }^{17}$ Thus, the presence of Hirano bodies in infections of the central nervous system caused by unconventional viruses may be potentially significant and not merely the result of a nonspecific neuronal degeneration.

Since in the present family no other possible or probable case could be ascertained before generation II and since the three affected sibs living in close physical contact died at different ages and with death intervals of 5 and 3 years, it is impossible to postulate either vertical transmission or common exposure to an environmental source of Creutzfeldt-Jakob disease virus. If lateral transmission occurred, incubation periods of between 3 and 5 years can be deduced. However, despite the fact that the mechanism responsible for familial cluster of Creutzfeldt-Jakob disease remains conjectural, the increasing high incidence of familial Creutzfeldt-Jakob disease in Chile points to a genetically inherited susceptibility to the infectious agent and to a better degree of case ascertainment. ${ }^{18}$

\section{References}

${ }^{1}$ Brownell B, Oppenheimer DR. An ataxic form of subacute presenile polioencephalopathy (CreutzfeldtJakob disease). J Neurol Neurosurg Psychiatry 1965;28:350-61.

${ }^{2}$ Masters CL, Gajdusek DC, Gibbs CJ Jr. CreutzfeldtJakob disease virus isolations from the GerstmannSträussler syndrome, with an analysis of the various forms of amyloid plaque deposition in the virusinduced spongiform encephalopathies. Brain 1981;104:559-88.

${ }^{3}$ Cartier L, Martin S, Gálvez S. Creutzfeldt-Jakob disease with kuru-like neuropathological features. Phronesis 1982;3:137-46.

4 Zarranz JJ, Rivera-Pomar JM, Salisachs P. Kuru plaques in the brain of two cases with Creutzfeldt-Jakob disease. J Neurol Sci 1979;43:291-300.

${ }^{s}$ Cobb W, Hornabrook RW, Sanders S. The EEG of kuru. Electroencephologr Clin Neurophysiol 1973;34:419-27.

- Gibbs CJ Jr, Gajdusek DC. Virus-induced subacute slow infections of the brain associated with a cerebellartype ataxia. In: Kark RAP, Rosemberg RN, Schut LJ, eds. Advances in Neurology. Vol 21. New York: Raven Press, 1978:359-72.

${ }^{7}$ Michel D, Tommasi M, Masson R, Rochet M, Berthezene F, Schott B. Encéphalopathie spongieuse tardive de type Creutzfeldt-Jakob avec importantes lesions cérébelleuses (Etude anatomo-clinique d'un cas). J Med Lyon 1968;49:575-92.

${ }^{8}$ Boudin G, Pépin B, Milhaud M. Maladie de Creutzfeldt-Jakob a symptomatologie cérébelleuse dominante (Etude anatomo-clinique d'un cas). Rev Neurol (Paris) 1965;113:73-5.

${ }^{9}$ Kott E, Bornstein B, Sandbank U. Ataxic form of Creutzfeldt-Jakob disease. Its relation to subacute spongiform encephalopathy. J Neurol Sci 1967; 5:107-13.

${ }^{10}$ Ogata J, Budzilovich GN, Cravioto H. A study of rodlike structures (Hirano bodies) in 240 normal and pathological brains. Acta Neuropathol (Berl) 1972;21:61-7.

"Hirano A, Malamud N, Elizan TS, Kurland LT. Amyotrophic lateral sclerosis and Parkinsonism-dementia complex on Guam. Arch Neurol 1966;15:35-51.

12 Ramsey MJ. Altered synaptic terminals in cortex near 
tumor. Am J Pathol 1967;51:1093-1109.

${ }^{13}$ Schochet SS Jr, Hardman JM, Ladewig PP, Earle KM. Intraneuronal conglomerates in sporadic motor neuron disease. Arch Neurol 1969;20:548-53.

${ }^{14}$ Llena JF, Hirano A. Abundant eosinophilic rod-like structures in subacute spongiform encephalopathy. $J$ Neuropathol Exp Neurol 1979;38:329.

15 Flament-Durand J, Couck AM. Spongiform alterations in brain biopsies of presenile dementia. Acta Neuropathol (Berl) 1979;46:159-62.
${ }^{16}$ David-Ferreira JF, David-Ferreira KL, Gibbs CJ Jr, Morris JA. Scrapie in mice. Ultrastructural observations in the cerebral cortex. Proc Soc Exp Biol Med 1968;127:313-20.

${ }^{17}$ Field EJ, Mathews JD, Raine CS. Electron microscopic observations on the cerebellar cortex in Kuru. $J$ Neurol Sci 1969;8:209-24.

${ }^{18}$ Gálvez S, Cartier L, Monari M, Araya G. Familial Creutzfeldt-Jakob disease in Chile. J Neurol Sci 1983;59:139-47. 